\title{
FORMAÇÃO INICIAL E A PRÁTICA PEDAGÓGICA DO PROFESSOR DE EDUCAÇÃO FÍSICA INICIANTE
}

\author{
INITIAL TRAINING AND PRACTICE OF TEACHING PHYSICAL EDUCATION \\ TEACHER BEGINNER
}

\section{FORMACIÓN INICIAL Y LA PRÁCTICA PEDAGÓGICA DEL PROFESOR DE EDUCACIÓN FÍSICA INICIANTE}

\author{
Victor Julierme Santos da Conceição* \\ Hugo Norberto Krug \\ Eduardo Batista von Borowski ${ }^{\text {th+ }}$ \\ Jéssica Serafim Frasson ${ }^{*+* x}$
}

\begin{abstract}
Resumo: O objetivo deste estudo é compreender como a formação inicial influencia a prática pedagógica de cinco professores de Educação Física no início da docência. Investigamos a trajetória e a prática educativa dos professores de Educação Física na fase de início da docência a partir de uma entrevista semi-estruturada. Em um processo de considerações transitórias, destacamos que os professores em início da docência, possuem dificuldades ao lidar com os alunos quanto ao domínio da turma, dificuldade de preparar a aula, de organizar um planejamento e de rotinizar no ambiente escolar, e ainda, colocam a formação inicial como um dos principais motivos desse problema, pois acreditam em um processo formativo definitivo. Já outros professores afirmam que o conhecimento nela adquirido é essencial, mas que se precisam continuar a busca pelo mesmo, para que sempre se possa refletir a sua prática pedagógica.
\end{abstract}

Palavras-chave: Formação Inicial. Professor Iniciante. Prática Pedagógica.

\begin{abstract}
The objective of this study is to understand how the initial training influences the pedagogical practice five physical education teachers at the start of teaching. We investigate the trajectory and the educational practice of physical education teachers in the beginning stage of teaching from a semistructured interview. In a process of transitional considerations highlight that beginning teachers, in teaching, have difficulties when dealing with students about the field of class, inability to prepare your lesson planning to organize and become routine in the school environment, and also put the initial training and one of the main reasons for this problem because they believe in a final training process. Have other teachers claim that her acquired knowledge is essential, but it must continue to search for the same, so you can often reflect their practice.
\end{abstract}

Keywords: Initial Training. Novice teacher. Pedagogical Practice.

Resumen: El objetivo de este estudio es comprender cómo la formación inicial influencia la práctica pedagógica de cinco profesores de Educación Física en el inicio de la docencia. Investigamos la

\footnotetext{
*Universidade Federal de Santa Catarina - UFSC. Email: victorjulierme@yahoo.com.br

**Universidade Federal de Santa Catarina - UFSC. E-mail: hnkrug@bol.com.br

***Instituto Federal de Santa Catarina - IFSC. Email: ebvb@unesc.net

**** Universidade Federal do Rio Grande do Sul - UFRS. Email: jehfrasson@hotmail.com
} 
trayectoria y la práctica educativa de los profesores de Educación Física en la fase de inicio de la docencia a partir de una entrevista semi-estructurada. En un proceso de consideraciones transitorias, destacamos que los profesores en inicio de la docencia, poseen dificultades al lidiar con los alumnos cuanto al dominio del grupo, presentan dificultad en preparar la clase, de organizar un planeamiento y de crear una rutina en el ambiente escolar y, aún, eligen la formación inicial como uno de los principales motivos de ese problema, pues creen en un proceso formativo definitivo. Ya otros profesores afirman sobre la importancia del conocimiento en ella adquirido, pero que su continuidad es esencial para la contribución de la verdadera función de la Educación Física en el contexto escolar.

Palabras-clave: Formación Inicial. Profesor Iniciante. Práctica Pedagógica.

\section{Considerações introdutórias}

Marcelo Garcia (2010) destaca que, no início do século XX, a profissão do professor detinha um status de maior importância, com um prestígio profissional muito amplo em que todos possuíam respeito pelos seus mestres. Para o autor, nos dias atuais, a formação de professores não é tarefa muito fácil, pois há uma grande insatisfação por parte da classe em exercício e, até, dos próprios formadores em relação às instituições de formação.

Esta insatisfação deriva de diversos fatores, tanto físico como psicológico: desvalorização da disciplina, salário, falta de materiais pedagógicos e infraestrutura, falta de apoio da organização escolar, a indisciplina dos alunos e a dificuldade em refletir sobre sua prática. Levamos em consideração que o construir-se professor envolve muito mais do que só prática, ou ainda só teoria, pois compreendemos a docência como elemento de constante aprendizagem e desenvolvimento profissional, em que o professor precisa estar atento às mudanças e transformações que ocorrem no cotidiano escolar.

Entendemos a formação como um processo importante no qual o objetivo é também proporcionar elementos para que os docentes em formação possam refletir e construam sua própria autonomia.
Dessa forma, a formação inicial é um momento em que os docentes incorporam e interiorizam muitos conhecimentos, pois possuem diversas vivências e experiências, com as disciplinas, conteúdos, prática como componente curricular e os estágios oferecidos pelo currículo do curso. Entretanto, no decorrer da carreira, revela-se a importância de o professor manter-se em processo de aprendizagem, ou seja, sempre buscando novos horizontes, novas reflexões, para que possa se manter atualizado e em constante processo reflexivo. Freire (1987) destaca a importância da busca do ser mais, mais reflexivo, mais crítico, autônomo, haja vista que um dos primeiros passos para isso é tomar a consciência do ser inacabado, do ser inconcluso, do professor pesquisador que inicia na formação inicial e deve perdurar por todo percurso docente.

Marcelo Garcia (2010) destaca que a formação inicial pode ser vista como um processo de desenvolvimento e estruturação do futuro docente, que se alcança com duplo efeito, de uma maturação interna e de possibilidades de aprendizagens e de experiências dos sujeitos. Assim, a formação de professores é entendida como um processo sistemático e organizado. O autor ainda afirma que os professores em formação ou os já formados desenvolvem, individualmente e/ ou em equipe, experiências de aprendizagem e, através delas, incorporam e interiorizam 
os seus conhecimentos e suas competências, permitindo, dessa forma, o constante intervir profissional.

Convém destacar que vários aspectos são estudados para entender a prática docente, tais como a formação inicial, continuada e permanente, a competência do professor, o seu desenvolvimento e o estudo da prática pedagógica. Neste estudo, damos preferência aos aspectos da formação docente.

Pérez Gómez (1995) afirma que as necessidades de estudos sobre a formação docente contribuíram para a superação de problemas enfocados em três polos interligados: dicotomia entre teoria acadêmica e prática docente; ir além do pensamento de que a formação inicial necessita ter como produto final um profissional pronto para atuar e encarar todas as realidades encontradas no cotidiano escolar; e a superação da ideia de que há uma relação entre os processos de ensino e os processos de aprendizagem. Nóvoa (1995) corrobora com a ideia enfatizando que

[...] a formação deve estimular uma perspectiva crítico-reflexiva, que forneça aos professores meios de um pensamento autônomo e que facilite as dinâmicas de auto-formação participada. [...] A formação não se constrói por acumulação (de cursos, de conhecimentos ou de técnicas), mas sim através de um trabalho de reflexividade crítica sobre as práticas e de (re)construção permanente de uma identidade pessoal. Por isso é tão importante investir na pessoa e dar um estatuto ao saber da experiência (NÓVOA, 1995 p.25).

Observamos, então, que a dicotomia entre teoria e prática é encontrada com frequência nos estudos sobre formação, pois alguns professores não conseguem fazer esta reflexão e analisar o seu contexto escolar dificultando a continuidade à sua prática educativa. A formação inicial, então, não tem como objetivo formar um produto, um indivíduo “pronto", pois ela não se dá apenas pela acumulação de conhecimentos, mas pela reflexão das práticas vivenciadas e experienciadas. Nesse sentido, destacamos que existem distintas culturas escolares, e o conhecimento está em constante transformação, de modo que compreendemos que a formação inicial não possui subsídios para dar conta de construir um professor completo, acabado. A formação oferece ao iniciante um leque de possibilidades e uma base teórica para que, a partir disso, o professor busque novos conhecimentos e se estabeleça na realidade em que se insere.

Molina Neto (1997) e Tardif (2002) afirmam que na formação inicial o professor precisa conhecer a sua realidade escolar, para assim poder tratar as suas aulas de acordo com a cultura de determinado lugar. Percebemos, então, a necessidade de novas compreensões de formação/atuação docente, entendendo que a função do professor se estabelece pelas interligações do conhecimento teórico, a cultura escolar e a reflexão sobre a prática docente a partir do próprio exercício da profissão (BARROS, 2008).

Medeiros e Conceição (2012) observam que o fazer docente é alimentado pelo contexto escolar e que é possível transformar os saberes em conhecimentos, aproximandose da realidade social. O processo de construir-se professor se desenvolve também com o tempo e com as experiências, pois com o tempo vai-se apreendendo e incorporando novas compreensões que ajudam os docentes iniciantes a enfrentar situações difíceis encontradas no cotidiano escolar. Talvez essas compreensões não sejam as mesmas aprendidas na formação inicial, mas essas novas situações levam a outros aprendizados e estimulam a ações inéditas, isto é, a, relacionar teoria e prática. 
Segundo Medeiros e Conceição (2012), a formação é um processo que ocorre ao longo da vida, passando por experiências vividas no decorrer de várias relações estabelecidas no contexto educacional; portanto a formação de um educador não se dá apenas na formação inicial e muito menos termina nela, ela também perpassa pelas experiências vivenciadas na Educação Básica.

No processo de formação contínua, Montalvão (2008) sugere a necessidade de formar docentes que reflitam sobre a sua prática escolar, de modo que essa reflexão sirva de ferramenta para desenvolver o pensamento e a ação. Quando mais houver docentes capazes de refletir sobre a sua prática, consequentemente haverá alunos mais críticos e mais motivados a buscarem conhecimentos. Nesse sentido, Freire (1996) estimula a reflexão sobre o professor pesquisador:

Não há ensino sem pesquisa e pesquisa sem ensino. Esses que-fazeres se encontram um no corpo do outro. Enquanto ensino continuo buscando, reprocurando. Ensino porque busco, porque indaguei e me indago. Pesquiso para constatar, constatando, intervenho, intervindo educo e me educo. Pesquiso para conhecer o que ainda não conheço e comunicar ou anunciar a novidade (FREIRE, 1996. p.29).

Assim, podemos afirmar que o professor faz o aluno, assim como a constante busca de conhecimento faz o professor. Segundo Nóvoa (1995) desenvolver a prática da reflexão nos professores seria um dos meios de construção dos saberes docente e da identidade profissional. Apesar de todo o conhecimento teórico ser primordial, a formação docente não se dá somente por esse meio, ou seja, não há por que termos vários cursos acumulados, se não soubermos a maneira certa de usufruirmos deles e quando e como utilizá-los.
Então, entendemos que esta formação precisa partir da reflexão crítica sobre as práticas, da (re)construção contínua da identidade profissional e também da própria identidade pessoal (MONTALVÃO, 2008). Nesse sentido, a prática educativa faz parte da construção das identidades profissionais, lembrando que não existe uma única identidade, mas o indivíduo passa por um processo de identização, pois, como não está inserido em único contexto de relações, deve ocorrer, como descreve Melucci (2004), a ressignificação da pluralidade do seu eu, através da reflexão e imersão nos diversos contextos.

Tendo em vista que o professor iniciante, em seu processo de construção, passa por dificuldades, medos, superações, descobertas, dificuldade em relacionar teoria e prática, apontamos o seguinte objetivo de pesquisa: compreender como a formação inicial influencia na prática pedagógica de cinco professores de Educação Física no início da docência.

\section{Procedimentos metodológicos}

Realizamos um estudo descritivo, de abordagem qualitativa, "que tem como pressuposto científico manipular informações recolhidas, descrevendo e analisando-as para num segundo momento interpretar e discutir à luz da teoria” (NEGRINE, 2010, p.62). Neste tipo de pesquisa, os instrumentos de investigação se referem a um processo de aprofundamento dos dados construídos junto aos colaboradores. Participaram cinco professores de Educação Física (três mulheres e dois homens), cujo primeiro critério de seleção foi a representatividade tipológica (de acordo com Molina Neto, 2010) levando em consideração o tempo de atuação docente e o fato de atuar em uma ou mais escolas do município de Criciúma, SC. 
Quadro 1: Caracterização dos colaboradores da pesquisa

\begin{tabular}{|c|c|c|c|c|}
\hline PROFESSORES $^{*}$ & SEXO & IDADE & TEMPO DE ATUAÇÃO & NÚMERO DE ESCOLAS \\
\hline Carmen & $\mathrm{F}$ & 24 & 3 & 01 \\
\hline Francisco & $\mathrm{M}$ & 25 & 4 & 02 \\
\hline Luiza & $\mathrm{F}$ & 24 & 3 & 01 \\
\hline Ana & $\mathrm{F}$ & 26 & 3 & 02 \\
\hline João & $\mathrm{M}$ & 23 & 2 & 01 \\
\hline
\end{tabular}

*os nomes dos colaboradores foram substituídos por fictícios

Os professores, ao aceitarem participar da entrevista, assinaram um termo de consentimento livre e esclarecido, e os seus nomes foram modificados para preservar a identidade e manter os aspectos éticos da investigação.

Como instrumento de coleta de dados com os colaboradores da pesquisa, utilizamos uma entrevista semiestruturada com questões elaboradas a partir de uma matriz analítica, que versaram sobre os objetivos da investigação. Negrine (2010) ainda afirma que, utilizando essa forma de entrevista, podemos garantir um emaranhado de informações importantes, além de que ela possui uma grande flexibilidade, pois através do diálogo deixa o entrevistado mais à vontade e possibilitando ao entrevistador realizar perguntas que não estejam no roteiro, desde que sejam relevantes ao assunto tratado.

As entrevistas foram agendadas, transcritas e passaram por um processo de validade interpretativa a partir da leitura pelos colaboradores do material transcrito. Esse movimento de validação do processo de construção das respostas às questões norteadoras da pesquisa culminou na elaboração das unidades de significado que deram sequência à construção das categorias de análise.

\section{Resultados e discussões: a influência da formação inicial na prática pedagógica do professor iniciante}

Recorrendo ao objetivo desta pesquisa, procuramos compreender a influência da formação inicial dos professores iniciantes e como essa formação contribuiu para a prática pedagógica na escola. Nessa busca encontramos elementos nas falas dos professores colaboradores que explicam esse processo de análise: ‘formação de professores', 'receitas prontas', 'aliar teoria e prática’, 'estágios obrigatórios e não obrigatórios’ e ‘sistematização do conteúdo (Como? O quê? Para quem?)’.

Assim, os colaboradores apresentaram em suas falas a importância do contexto formativo para a trajetória docente. Ressaltamos que, ao se falar em 'formação de professores', podemos encontrar inúmeras pesquisas nos últimos anos, pois é uma temática que vem sendo abordada e discutida por vários autores, os quais foram utilizados no decorrer do texto.

Neste sentido, Migliorança (2010) afirma que as experiências e conhecimentos adquiridos na formação inicial, durante o processo de formação, não são os únicos elementos que influenciam na prática docente. É possível encontrar nas falas dos professores uma determinada importância atribuída à formação inicial, além de se perceber que cada professor agrega um objetivo a sua formação: 
"O objetivo é fazer com que aquele cidadão, aquele indivíduo que está ali buscando aquela formação se torne professor, capaz de atuar nas escolas, que possa sair pronto para encarar a realidade" (prof ${ }^{a}$ Ana).

"O objetivo seria formar professores capazes de atuar, e nessa formação ele precisa ter um grande auxílio, uma grande base teórica para poder aplicar seus conhecimentos na sua prática do dia-a-dia" (prof ${ }^{a}$ Luiza).

"Eu acredito que a formação inicial do professor é para te dar uma base, pois vai ser onde tu vai pisar, e essa base tem que ser bastante sólida. Se tu não tiveres uma boa base, tudo que tu fizer dali para frente será difícil, é igual fazer um prédio, se ele não tiver uma boa estrutura, ele vai cair" (prof. Francisco).

Observa-se nessas falas a perspectiva que os professores possuem sobre a formação. Para o professor Francisco, a formação é também a construção de uma base teórica, ou seja, a gama de conhecimentos, para, a partir dessa bagagem adquirida, poder realizar suas práticas educativas.

É possível perceber na fala das professoras Ana e Luiza que a formação inicial precisa tornar os professores prontos para atuar, mas o que é passado para eles não é suficiente para o cotidiano encontrado nas escolas. Assim, os colaboradores apontam elementos que nos fazem pensar em outra questão, que chamamos de 'receita pronta', e, nesse sentido, a professora Luiza afirma que a formação inicial precisa oferecer todas as formas possíveis de trabalhar na Educação Física, mas que ela não cumpre com o seu papel.

“É muito substancial... [...] o estágio obrigatório que temos é importante, mas é pouco tempo e a base teórica na faculdade é muito pouca, não dá conta de suprir as necessidades" (prof ${ }^{a}$ Luiza).
Como a fala da professora Carmem, entendemos a formação como uma constante busca de conhecimento, ou seja, ao terminar a graduação, os professores não estão prontos, pois sempre terão novas dúvidas e anseios a serem esclarecidos, novas aprendizagens a serem alcançadas. E isso precisa partir do professor. Freire (1996) salienta que educar é como viver que exige a consciência do inacabado, pois o ato de ensinar/aprender necessita ser permanente. É necessária a consciência de que as pessoas podem ser condicionadas de acordo com o meio. Assim, pode-se perceber que as realidades encontradas são distintas, e que o professor é um ser inacabado, sempre buscando conhecimento.

“Tudo vem da prática cotidiana, das vivências, vai do professor também ir à busca de conhecimentos, de novos horizontes. Pois nunca ninguém sai pronto, tudo vai se moldando conforme as necessidades $e$ dificuldades encontradas nas várias realidades escolares" (prof ${ }^{a}$ Carmem).

A diferença na postura aparece nas falas dos entrevistados, em que uns acreditam na formação continuada, e outros pensam na formação única. Nesse sentido, Betti (1992) diz:

o processo de formação profissional não termina na universidade. Uma profissão deve não apenas colocar em prática, de forma socialmente útil, os conhecimentos existentes, mas ser capaz de absorver novos conhecimentos, na medida em que se tornam disponíveis na disciplina acadêmica, modificando e aperfeiçoando a sua prática (BETTI, 1992, p.241).

Analisando esta reflexão, podemos perceber como os professores necessitam de uma 'constante busca pelo conhecimento', pois a sociedade está sempre em transformação, e os professores precisam procurar meios para 
entender esse processo. Um dos colaboradores aponta essa questão em uma das suas falas sobre a formação inicial:

"Eu digo que ela poderia oferecer mais, eu percebi que na minha formação (inicial) muitas coisas me faltaram, e muitas coisas não eram tão necessárias, isso no meu entendimento. Talvez para quem construiu a grade (Curricular), naquele momento histórico, pensou ser interessante, e entendeu que aquilo era necessário, como prova, ela está sempre em transformação, sempre sendo adaptada para um melhor desempenho. [...] Mas o professor não deve ficar só nisso, ir buscar o conhecimento além, aí parte da iniciativa do professor, como Paulo Freire fala: o professor é um eterno pesquisador” (prof. Francisco).

Medeiros e Conceição (2012) nos ajudam a compreender que as situações de estresse, que geram dificuldades no início da docência, necessitam de um processo na formação inicial cuja autonomia seja o ponto central. Podemos perceber que o professor Francisco reconheceu a importância do conhecimento obtido na formação inicial, mas compreende que a prática docente é feita de muitas reflexões a partir do seu contexto escolar.

Caldeira (2001) ressalta sobre a importância da estimulação da reflexividade a partir da formação inicial, quando é preciso se apropriar da reflexão para ressignificar a prática educativa cujo processo é contínuo. "Por mais completa que seja a formação inicial, é por meio da prática docente reflexiva que o professor continua seu processo de formação na escola” (CALDEIRA, 2001, p.89).

Outro elemento que surgiu nas falas dos colaboradores foi a dificuldade em 'aliar teoria e prática’. Para Ferreira (2005) na formação docente a prática precisa ser revista pela teoria por meio de reflexão crítica, de forma que se possam buscar processos que possibilitem aos docentes ampliar seus conhecimentos, assim podendo buscar novas formas de superar as dificuldades comprometendo-se com a sua profissão. “[...] os professores como profissionais práticos, não produzem saberes só com a prática. A teoria tem um importante papel nesse processo e, sem trabalho de reflexão (teórica) é impossível avançar a análise da prática” (CALDEIRA, 2001, p.91).

Percebemos que uma compõe a outra, e que teoria e prática necessitam ser trabalhadas pelo professor como um todo. O Conselho Nacional de Educação (CNE)/Conselho Pleno (CP), quando instituiu as Diretrizes Curriculares Nacionais para a formação de docentes, apontou:

[...] As competências tratam sempre de alguma forma de atuação, só existem “em situação” e, portanto, não podem ser aprendidas apenas no plano teórico nem no estritamente prático. A aprendizagem por competências permite a articulação entre teoria e prática e supera a tradicional dicotomia entre essas duas dimensões, definindo-se pela capacidade de mobilizar múltiplos recursos numa mesma situação, entre os quais os conhecimentos adquiridos na reflexão sobre as questões pedagógicas e aqueles construídos na vida profissional e pessoal, para responder às diferentes demandas das situações de trabalho (BRASIL, 2001, p.28-29).

Segundo o Parecer n.009 do CNE/CP (BRASIL, 2001), as formas de atuação não podem ser divididas, uma hora só em planos teóricos e outro momento só prática. Essa abordagem permite que ambas se articulem, pois assim todo o conhecimento teórico obtido fará sentido com a bagagem prática e vice-versa, ou seja, uma depende da outra para um melhor resultado. Analisando essa questão, temos outra face, aquela em que os professores procuram entender esse conjunto 
e repensar seus atos sobre a docência, ou seja, refletir sobre suas aulas e assim ressignificar a ideia de que não temos a teoria e depois a prática ou vice versa, mas um conjunto.

“Eu entendo a 'teoria e a prática' como dois momentos de um acontecimento só, elas têm uma interligação muito forte, eu não entendo a teoria e depois a prática, uma está interligada a outra e uma só surge junto com a outra, uma é um complemento da outra. [...] Planejar uma aula a partir da teoria que tive, não é um fator de dificuldade, o que dificulta talvez seria a falta de experiência de executar a aula que a gente planejou. A partir do momento que eu consegui realizar o meu planejamento eu acredito que eu consegui trabalhar com as duas, e se eu não consegui talvez eu não tenha feito a análise dos meus alunos" (prof. João).

O professor João demonstra estar ciente do conjunto teoria e prática, pois percebe em suas aulas a relação, às vezes com mais frequência, às vezes não, mas que sempre acontecem juntas. Assim, podemos analisar que a dificuldade não está em trabalhar esse conjunto, pois na maioria dos casos os professores conseguem conciliar teoria e prática, só que não percebem isso, por não compreender o que é a práxis pedagógica. Assim nos debruçamos em Freire (1987, p.21) para manifestar nosso entendimento sobre a práxis como “ a reflexão e ação dos homens sobre o mundo para transformá-lo [...].”

Então partindo do entendimento que a práxis pedagógica é que baliza o ato de reflexão sobre a prática educativa, percebemos que essa falta de compreensão dos colaboradores sobre teoria e prática pode acontecer pela falta de experiência dos iniciantes em lidar com essas situações imprevistas. Temos aí duas situações distintas: uma, em que os professores iniciantes têm apenas como experiência o estágio obrigatório oferecido pela formação inicial; a outra seria quando os iniciantes buscam estágios não obrigatórios, oferecido por prefeituras, fundações e etc. para trabalhar.

Outro elemento que surgiu, a partir das falas dos professores, foram os 'estágios obrigatórios e não obrigatórios', sobre os quais Canário (2001, p.40) afirma que “o estágio favorece a construção significativa de aprendizagens tanto para alunos, quanto para o professor que atua nas escolas-campos”.

Em Krug et al. (2008) observamos que o estágio é concebido como uma experiência, ou seja, como um conjunto de vivências significativas por meio das quais o estagiário identifica, seleciona, destaca os conhecimentos necessários e válidos para a atividade profissional.

Assim, os estágios podem oferecer aos acadêmicos e futuros docentes as realidades de atuações em diferentes espaços, realidades e culturas. E cada colaborador atribui um significado a sua vivência com o estágio, o que observamos nas falas a seguir:

\footnotetext{
"Os estágios obrigatórios te mostram pouco da realidade, não nos prepara para o dia-a-dia escolar. A insegurança é um grande fator, pois temos várias turmas $e$ temos que enfrentar os problemas com os próprios alunos, pais e professores" (prof ${ }^{a}$ Carmem).
}

“Os estágios obrigatórios são bons, mais o estágio é uma coisa muito pequena pela quantidade de coisas que a gente faz" (prof ${ }^{a}$ Luiza).

Isto demonstra que os professores iniciantes pensam que a formação inicial precisa necessariamente proporcionar-lhes todas as realidades, não percebendo que essa prática é sim de reconhecimento, e que há distintas realidades assim como várias outras dificuldades a serem encontradas e superadas por eles. 
O estágio, para alguns acadêmicos, tem pequena importância, já, para outros, ele representa uma questão significativa, pois, às vezes, é o único momento em que possuem contato com a escola. O estágio é central no debate sobre formação inicial, principalmente quando é percebido como elemento de descoberta sobre as culturas da escola. É percebível a procura de alguns acadêmicos pelos estágios não obrigatórios, para ganho de experiência. Com esse contato direto no ambiente escolar eles podem refletir sobre sua prática e ressignificá-la.

"Eu tive maior facilidade porque eu procurei um 'estágio não obrigatório’ para fazer, [...] eu fui atrás, já queria estar no ambiente escolar antes de ter uma turma em minhas mãos" (prof ${ }^{a}$ Luiza).

"Para mim eu vou dizer que foi fácil, tendo em vista que tive alguns 'anos de estágios', eu peguei várias realidades, trabalhei em realidades difíceis, outras mais tranquilas e várias idades. Então acredito que se não fosse o 'estágio', eu não estaria preparado pra encarar tudo, eu ia passar bastante trabalho" (prof. Francisco).

Observamos em Pimenta (2006, p.75) que “o estágio deve ser um momento de síntese dos conteúdos, das matérias de ensino, das teorias de aprendizagem e das experiências pessoais, bem como deve constituir-se em um processo de reflexão-ação-reflexão [...]”. Assim sendo, podemos refletir e fazer uma ligação entre a ideia da autora e as falas dos colaboradores, para os quais os estágios servem de subsídios para os acadêmicos que procuram por experiências práticas na área docente, pois assim já têm contato com acontecimentos e a realidade do campo de atuação, adquirindo uma visão do que está por vir no processo de construção da carreira docente. E quando os colaboradores colocam que, se não fossem esses estágios, não teriam condições de trabalhar, tanto pela própria falta de experiências quanto pela falta de domínio da turma.

Para os professores iniciantes ter a sua própria turma, os seus alunos é algo importantíssimo, mas um tanto quanto difícil, pois ainda não possuem domínio, não conseguem lidar com as situações indesejáveis, e isso em alguns casos pode desmotivá-los. Assim, é importante que haja uma rede de amparo aos professores iniciantes, pois essa falta de segurança pode acarretar certas dificuldades que podem ser irreversíveis, chegando até mesmo ao abandono da docência.

Partindo desta angústia dos colaboradores, apontamos o que eles chamam de 'sistematização de conteúdos (Como? O quê? Para quem?)', ou seja, os professores ainda não estão seguros do que ensinar, a quem ensinar e como ensinar, e isso é possível observar nas falas e discussões a seguir, em que aparece a instrumentalização do conhecimento, segundo a qual seria mais fácil possuir um livro didático, uma apostila da área em questão.

O professor Francisco aponta esta questão da seguinte forma:

"A Educação Física está muito insegura na
forma de ensinar. Em Português tu tem bem
norteado, até tal ano o aluno tem que estar
lendo, até tal ano o aluno tem que estar in-
terpretando, até tal ano o aluno tem que es-
tar produzindo texto. Já a Educação Física
eu vejo ela assim sem essa preocupação
de como, pra que, e o que ensinar" (prof.
Francisco).

A partir desta fala, podemos perceber que há preocupação com o andamento da disciplina, e que existem dúvidas sobre os conteúdos da Educação Física. Nos Parâmetros Curriculares Nacionais - PCNs (BRASIL, 1997) temos os pilares da Educação Física e várias formas de trabalhá-los. Os professores, 
além disso, possuem a liberdade de escolher como trabalhar esses conteúdos da melhor forma possível. Talvez os professores pensem na 'sistematização', na ‘instrumentalização’ e se furtem de analisar o contexto em que lecionam, as realidades nas quais estão inseridos.

Talvez falte por parte dos professores a análise de conjuntura, ou seja, analisar toda a organização escolar e refletir se ela está de acordo, para receber essa 'sistematização', essa aula pronta, com atividades e teoria com os mesmos níveis e igualitária, ou se seria melhor possuir essa liberdade de escolher os conteúdos e trabalhá-los da forma que for mais adequada à escola, à sua escola.

\section{Considerações transitórias}

No processo de construção das considerações transitórias deste estudo, resgatamos, neste momento, o objetivo principal tratado na investigação: compreender como a formação inicial influencia a prática pedagógica de cinco professores de Educação Física no início da docência. Compreendemos que a formação inicial tem como um de seus objetivos auxiliar os acadêmicos para que possam futuramente exercer a profissão, mas que ela não dá conta de mostrar e ensinar tudo o que os professores precisam saber, pois isso só é possível no decorrer da sua vida profissional, na qual as suas experiências irão se concretizando por elas através das suas reflexões e ressignificações.

É possível perceber nas entrevistas que a profissão de professor está muito desvalorizada, tanto na questão salarial como pelo sentido que a ela se atribui atualmente. No caso da Educação Física, essa questão da desvalorização da própria disciplina pelos demais professores do corpo docente acontece quando os docentes apontam que não se sentem integrados no contexto, pois não possuem um acolhimento institucional que faça o iniciante se sentir seguro.

A formação inicial é o grande alicerce do professor iniciante, pois é nela que ele se apoia para iniciar a sua docência. Mas é importante lembrar que o professor não sai da formação inicial pronto para desempenhar o seu papel de docente pelo resto de sua vida, ou seja, o professor iniciante precisará sempre ir em busca do conhecimento e procurar formas para que sua formação seja contínua. A sociedade muda, bem como os indivíduos que a constituem, sendo assim, o professor é um ser inconcluso, pois sempre precisará buscar soluções, conhecimentos, para que possa qualificar sua prática educativa.

Durante o desenvolvimento das entrevistas, percebemos que a questão mais elencada pelos docentes sobre a formação inicial é a dificuldade existente em aliar a teoria com a prática. Aprendemos, ainda, que não é o fato de não terem esse subsídio na universidade, mas sim o fato de não conseguirem fazer essa relação e refletir sobre esses dois elementos. Essa dificuldade pode surgir como produto de uma intensificação do trabalho docente, fazendo com que, pela extensa carga de trabalho, o docente não tenha subsídios para refletir, dar continuidade e avançar em sua prática educativa.

Compreendemos também que o docente, ainda em sua formação, por vezes não compreende a importância de aliar a teoria apreendida nos cursos de formação inicial à prática pedagógica. Deste modo, nos questionamos sobre a intencionalidade da prática pedagógica dos professores, pois, da maneira como está apresentada, os docentes tomam como subsídio suas vivências em um ambiente de instrumentalização do conhecimento, criado enquanto acadêmico junto à imediaticidade social, que faz com que o futuro professor utilize sua formação inicial 
para buscar 'manuais prontos' que deveriam dar conta em solucionar desafios do cotidiano escolar. Assim, ressaltamos a importância de continuar investigando a formação inicial dos professores, para que se compreenda a sua importância, a sua função, a fim de que, a partir daí, se possa contribuir para a importância do processo de ensino e de aprendizagem da Educação Física e que se evidencie a inegável contribuição da disciplina no universo escolar.

\section{Referências}

BARROS, A. M. R. Dificuldades e superações nos anos iniciais da docência em matemática das escolas públicas, 2008. Dissertação (Mestrado em Educação) - Universidade Metodista de Piracicaba, Piracicaba, 2008.

BETTI, M. Perspectiva na formação profissional. In: MOREIRA, W.W. (Org.). Educação física e esporte: perspectiva para o século XXI. Campinas: Papirus, 1992.

BRASIL. Parâmetros curriculares nacionais: Educação Física. Brasília: SEF/MEC, 1997.

BRASIL. Conselho Nacional de Educação. Parecer CNE/CP n. 009/2001. Diretrizes Curriculares Nacionais para a formação de professores de Educação Básica, em nível superior, curso de licenciatura, de graduação plena. Brasília, 8 de maio de 2001.

CALDEIRA, A. M. S. A formação de professores de educação física: quais saberes e suas habilidades? Revista Brasileira de Ciências do Esporte, Florianópolis, v.22, n.3, p.87-103, mai., 2001.

CANÁRIO, R. A prática profissional na formação de professores. In: CAMPOS, B. P. Formação profissional de professores no ensino superior. Porto: Porto Editora, 2001.
FERREIRA, L. A. O professor de educação física no primeiro ano da carreira: análise da aprendizagem profissional a partir da promoção de um programa de iniciação à docência, 2005. Tese (Doutorado em Educação) - Universidade de São Carlos, São Carlos, 2005.

FREIRE, P. Pedagogia da autonomia: saberes necessários à prática educativa. São Paulo: Paz e Terra, 1996.

. Pedagogia do oprimido. Rio de Janeiro: Paz e Terra, 1987.

KRUG, H.N. et al. Estágio curricular supervisionado em educação física: significado e importância sob a ótica dos acadêmicos do curso de licenciatura. In: SIMPÓSIO NACIONAL DE EDUCAÇÃO FÍSICA, XXVII, 2008, Pelotas. Anais... Pelotas: UFPEL, 2008.

MARCELO GARCIA, C. O professor iniciante, a prática pedagógica e o sentido da experiência. Revista Formação Docente, Belo Horizonte, v.03, n.03, p.1149, ago./dez., 2010. Disponível em: http:// formacaodocente.eutenticaeditora.com.br. Acesso em: 22 nov. 2013.

Formação de professores: para uma mudança educativa. Porto: Porto Editora, 1999.

MEDEIROS, C. R.; CONCEIÇÃO, V. J. S. da. Trajetória docente de professores de educação física na fase de entrada na carreira: um estudo sobre saberes mobilizados para a construção da identidade docente. In: VI Congresso SulBrasileiro de Ciências do Esporte, 2012, Rio Grande. Anais... 2012. v. 1. p. 1.

MELUCCI, A. O jogo do eu: a mudança de si em uma sociedade global. São Leopoldo: Ed. UNISINOS, 2004. 
MIGLIORANÇA, F. Programa de mentoria da UFSCar e desenvolvimento profissional de três professoras iniciantes, 2010. Tese (Doutorado em Educação) Universidade Federal de São Carlos, São Carlos, 2010.

MOLINA NETO, V. Etnografia: uma opção metodológica para alguns problemas e investigação no âmbito da Educação Física. In: MOLINA NETO, V.; TRIVIÑOS, A. N. S. A pesquisa qualitativa em educação física: alternativas metodológicas. 3. ed. Porto Alegre: Sulina, p 113 - 146, 2010.

A cultura do professorado de educação física das escolas públicas de Porto Alegre. Revista Movimento, Porto Alegre, v.4, n.7, p.34-42, 1997.

MONTALVÃO, E. C. O desenvolvimento profissional de professoras iniciantes mediante um grupo colaborativo de trabalho, 2008. Tese (Doutorado em Educação) - Universidade Federal de São Carlos, São Carlos, 2008.

NEGRINE, A. Instrumentos da coleta de informações na pesquisa qualitativa. In: MOLINA NETO, V.; TRIVIÑOS, A. N. S. A pesquisa qualitativa na educação física: alternativas metodológicas. $3^{\circ}$ ed. Porto Alegre: Sulina, p 61 - 93, 2010.

NÓVOA, A. Formação de professores e profissão docente. In: NÓVOA, A. (Coord.). Os professores e a sua formação. 2. ed. Lisboa: Publicações Dom Quixote, 1995. p.15-34.

PÉREZ GÓMEZ, A. O pensamento prático do professor: a formação do professor como profissional reflexivo. In: NÓVOA, A. (Org.). Profissão professor. $2^{\circ}$ ed. Porto: Porto Editora, 1995. p.93-114.
PIMENTA, S. G. O estágio na formação de professores - unidade teoria e prática? São Paulo: Cortez, 2006.

TARDIF, M. Saberes docentes e formação profissional. Petrópolis: Vozes, 2002. 